УДК 616.716.8.-018.46-002-06-078.73

DOI: $10.15587 / 2313-8416.2015 .36524$

\title{
СОСТОЯНИЕ ЦИТОКИНОВОГО СТАТУСА БОЛЬНЫХ ВЯЛОТЕКУЩИМ ОСТРЫМ ОДОНТОГЕННЫМ ОСТЕОМИЕЛИТОМ ЧЕЛЮСТЕЙ
}

\author{
(C) Н. Г. Баранник, С. Д. Варжапетян
}

\begin{abstract}
Методом твердофазного иммуноферментного анализа (тест-система ООО «Цитокин») определена концентрация циттокинов (ИЛ-1, ФНОА, ИЛ-6, ИЛ-4) в сыворотке крови 21 пациента с острым одонтогенным остеомиелитом челюстей и 21 здоровых лии. Выявлено достоверное увеличение в сыворотке

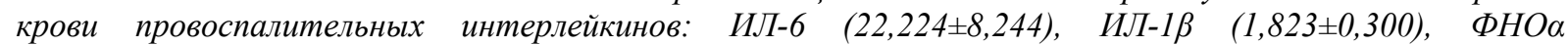

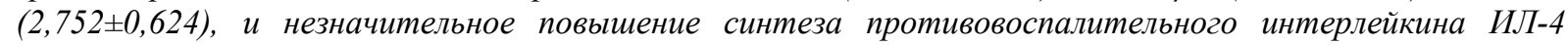
$(0,462 \pm 0,064)$
\end{abstract}

Ключевые слова: иммунологический статус, острый одонтогенный остеомиелит челюстей, интерлейкиньl

The content of IL-1 $\beta$ in the serum level was 1,823 $\pm 0,300(p<0.001)$, which is approximately 14.7 times the value of this indicator in healthy individuals - control group $(0,124 \pm 0,026)$. The concentration of TNF $\alpha$ in the blood of healthy individuals was 0,196 $\pm 0,023$, while in patients with acute odontogenic osteomyelitis occurs without acute clinical symptoms, observed an increase in the corresponding rate to 2,752 $\pm 0,624(p<0.001)$, almost 14 times. In the study group, it was also a sevenfold increase in the synthesis of IL-6 (22,224 18,244 ; $p<0.001)$ compared with the control group $(3,158 \pm 0,214)$.

The content of anti-inflammatory factors, immunological protection of organism (IL-4) in patients with odontogenic osteomyelitis at admission was 0,462 $\pm 0,064$, which was a statistically significant increase $(p>0,05)$ compared with those in the control group - 0,416 $\pm 0,058$

Keywords: immunological status, acute odontogenic osteomyelitis of the jaws, interleukins

\section{1. Введение}

По оценкам ряда отечественных и зарубежных авторов среди пациентов отделений челюстнолицевой хирургии удельный вес больных с острыми гнойно-воспалительными заболеваниями превышает $60 \%$ и имеет тенденцию к росту [1]. Одним из наиболее серьезных по своим последствиям гнойно - воспалительных заболеваний является остеомиелит челюстей (Маланчук В. А., 2014), в патогенезе которого важную роль играет дисбаланс в системе цитокинов: уровень провоспалительных цитокинов прямо зависит от степени и стадии развития остемиелита [2].

В последние годы отмечается изменение характера клинического течения воспалительных процессов челюстно-лицевой области, характеризующееся вялым и затяжным течением со склонностью к хронизации и развитию осложнений [3-5]. При остеомиелите челюстией патология редко диагностируется в острой и подострой стадиях [6]. Проведенный нами ретроспективный анализ историй болезней показал, что у 78 \% больных, госпитализированных в стационар, острый одонтогенный остеомиелит протекает без выраженной симптоматики, а частота диагностических ошибок при первичном обследовании данного контингента больных превышает 48 \% [7].

Такие пациенты, как правило, поступают в стационар в подостром периоде болезни, после неэффективного амбулаторного лечения. По данным литературы погрешности в лечении заболеваний челюстно-лицевой области достигают 40-75 \% [8]. Нарушение иммунной регуляции защитных механизмов организма, вследствие неадекватного приема антибактериальных препаратов, рассматривается как одна из причин хронизации воспалительных заболеваний челюстей $[9,10]$.

В свете сказанного особую важность обретает изучение иммунного состояния пациентов с вялотекущим острым одонтогенным остеомиелитом челюстей как одного из объективных показателей заболевания.

\section{2. Обзор зарубежной литературы}

Особое место в гнойной хирургии отводится надлежащей дифференциальной диагностике различных форм остеомиелита челюстей, так как окончательного диагноз определяет выбор правильного комплексного лечения [12]. В условиях амбулаторно-поликлинического и- стационарного звена, любое острое хирургическое заболевание должно распознаваться незамедлительно [13]. Однако это не подтверждается практической деятельностью лечебно-диагностических учреждений. Многие исследователи [14] отмечают недостаточную информативность «традиционных способов» диагностики остеомиелита в ранней стадии его развития. Особая сложность возникает при диагностике гипоэргического (вялотекущего) одонтогенного остеомиелита из-за не выраженности клинических симптомов. Вследствие этого, врачами всех уровней и специальностей как на догоспитальном, так и на госпитальном этапах, допускается большой процент диагностических ошибок.

\section{3. Цель исследования}

Определить состояние цитокиновый статус больных с гипоэргическим типом течения острого одонтогенного остеомиелита челюстей. 


\section{4. Материал и методы иссследования}

В биохимическом исследовании приняли участие 42 человека: 21 пациента с острым одонтогенным остеомиелитом челюстей (основная группа): у 3 (14,3 \%) больных воспалительный процесс локализовался на верхней челюсти, у 18 (85,7 \%) - на нижней, и 21 человек - здоровые лица (группа сравнения).

Выбор пациентов осуществляли методом простого случайного отбора (простая случайная выборка - Simple Random Sampling - SRS).

Критерием включения в основную группу был гипоэргический тип течения острого одонтогенного остеомиелита одной из челюстей. Клинический диагноз ставили на основании данных анамнеза, клинических (опрос, осмотр, пальпация, перкуссия, анализ крови и мочи) и параклинических (рентгенография, компьютерная томография) методов исследования, согласно требованиям, изложенным в «додаток до наказу MO3 № 566 від 23-11-2004». Диагностическими критериями были данные приведенные в литературе [1].

Критерием исключения были вторичные иммунодефицитные состояния, употребление наркотических препаратов в анамнезе.

Критерии включения в контрольную групп практически здоровые лица без хронических заболеваний внутренних органов и эндокринной системы.

Клиническая часть работы выполнена на базе кафедры хирургической и терапевтической стоматологии ГЗ «ЗМАПО МЗ Украины» в отделении хирургической стоматологии и челюстно-лицевой хирургии КУ «ГКБЭ и СМП г. Запорожья» (заведующая кафедрой доктор мед. наук, профессор Баранник Н. Г.). Иммунологические исследования выполнены в биохимической лаборатории ГЗ «ЗМАПО МЗ Украины».

Все исследования проведены в соответствии с постановлением Комитета по вопросам биоэтики при Президиуме НАН Украины (Постановление Прези- диума НАН Украины от 07.11.2007 г. № 288).

Для определения концентрации цитокинов в сыворотке крови периферическую кровь в объеме 5 мл получали из локтевой вены в асептических условиях, помещали в стерильные пробирки, содержащие 25 ЕД гепарина на 1 мл крови, центрифугировали при 3000 об/мин в течении 10 минут. Сыворотку разливали по 0,3 мл в пластиковые пробирки, замораживали и хранили до использования при $-20^{\circ} \mathrm{C}$. Определение концентрации цитокинов - ИЛ-1, ФНО $\alpha$, ИЛ-6, ИЛ-4 в сыворотке крови проводили методом твердофазного иммуно-ферментного анализа с использованием коммерческих тест-систем ООО «Цитокин» (Санкт-Петербург) в соответствии с инструкциями по их постановке. Результаты регистрировали по уровню оптической плотности, измеряемой при 450 нм на спектрофотометре, анализаторе Sunrise (Австрия). Количество цитокинов определяли путем построения калибровочной кривой с помощью компьютерной программы “Calibration” и выражали в пикограммах на мл.

Статистический анализ проведен с использованием пакета программ "Microsoft Excel 2007. Полученные данные подвергали статистической обработке методом вариационной статистики с определением средней арифметической (М) и стандартного отклонения (m). Статистически достоверные различия оценивали с помощью критерия СтьюдентаФишера (t).

\section{5. Результаты исследования и их обсуждение}

В результате биохимического исследования было выявлено повышение концентрации провоспалительных и противовоспалительных цитокинов в сыворотке крови пациентов с острым одонтогенным остеомиелитом челюстей.

Полученные данные свидетельствуют об угнетении защитных факторов иммунной системы (табл. 1).

Таблица 1

Содержание про- и противовоспалительных интерлейкинов в крови больных острым одонтогенным остеомиелитом

\begin{tabular}{|c|c|c|}
\hline Исследуемые показатели, (пг/мл) & \multicolumn{2}{|c|}{ Исследуемые группы } \\
\hline Интерлейкины & $\begin{array}{c}\text { Больные острым одонтогенным остео- } \\
\text { миелитом } \\
\mathrm{M} \pm \mathrm{m} \\
\mathrm{n}=21\end{array}$ & $\begin{array}{c}\text { Контрольная группа } \\
\mathrm{M} \pm \mathrm{m} \\
\mathrm{n}=21\end{array}$ \\
\hline Ил-1 & $\begin{array}{c}1,823 \pm 0,300 \\
\mathrm{p}<0,001\end{array}$ & $0,124 \pm 0,026$ \\
\hline Ил-6 & $\begin{array}{c}22,224 \pm 2,068 \\
\mathrm{p}<0,001\end{array}$ & $3,158 \pm 0,214$ \\
\hline ФНО & $\begin{array}{c}2,752 \pm 0,624 \\
\mathrm{p}<0,001\end{array}$ & $0,196 \pm 0,023$ \\
\hline Ил-4 & $\begin{array}{c}0,462 \pm 0,064 \\
\mathrm{p}>0,05\end{array}$ & $0,416 \pm 0,058$ \\
\hline
\end{tabular}

Примечание. $p$-сравнение показателей исследуемой группы с контрольной группой

Содержание ИЛ-1 $\beta$ в сыворотке крови больных острым одонтогенным остеомиелитом челюстей, протекающем без выражненной клинической симптоматики, на момент поступления в стационар находилось на уровне $1,823 \pm 0,300$ ( $<<0,001)$, что прибли- зительно в 14,7 раза превышало значение данного показателя у здоровых лиц - контрольная группа $(0,124 \pm 0,026)$. Концентрация ФНО $\alpha$ в крови пациентов $(2,752 \pm 0,624, \mathrm{p}<0,001)$ была в 14 раз больше, чем у здоровых лиц $(0,196 \pm 0,023)$. В исследуемой группе 
отмечено семикратное возрастание синтеза ИЛ-6 $(22,224 \pm 8,244, \mathrm{p}<0,001)$ в сравнении с контрольной группой $(3,158 \pm 0,214)$.

Содержание противоспалительных факторов иммунологической защиты организма (ИЛ-4) у пациентов с одонтогенным остеомиелитом при поступлении в стационар составил $0,462 \pm 0,064$, что явилось статистически недостоверным повышением ( $>0,05)$ по сравнению с лицами контрольной группы $0,416 \pm 0,058$. Незначительные изменения интенсивности синтеза противовоспалительного фактора (ИЛ- 4) при высоком содержании в крови провоспалительных цитокинов указывает на состояние иммунодепрессии, обуславливающей гипоэргический тип защитного ответа организма. Дисбаланс цитокинов обусловлен нарушением функции системы моноцитов/макрофагов, которые самостоятельно продуцируют ИЛ-4, тормозящий миграцию в очаг воспаления нейтрофилов и макрофагов. По данным ряда авторов [15] синтез ИЛ-4 может тормозиться активированными компонентами комплемента $\mathrm{C}_{3 \mathrm{a}}$ и $\mathrm{C}_{5 \mathrm{a}}$, a повышение его продукции, обусловлено усилением синтеза некоторыми клетками как компенсаторный ответ на воспаление в патогенезе острого одонтогенного остеомиелита [13].

Провоспалительные и противовоспалительные интерлейкины сыворотки крови могут быть использованы в практической медицине в качестве диагностических маркеров (с учетом полученных нами показатели) для распознания острого одонтогенного остеомиелита челюстей, протекающей без выраженной клинической симптоматики.

\section{6. Выводы}

1. Гипоэргический тип остеомиелита челюстей протекает в условиях достоверного повышения содержания в сыворотке крови провоспалительных интерлейкинов: ИЛ-6 $(22,224 \pm 8,244)$ - в 7 раз, ИЛ-1 $(1,823 \pm 0,300)$ - в 14,7 раза ФНО $(2,752 \pm 0,624)-$ в 14 раз при слабой активности синтеза противовоспалительного интерлейкина ИЛ-4 $(0,462 \pm 0,064)-$ всего в 1,1 раз.

2. Дисбаланс в системе имунного ответа макроорганизма при вялотекущем остром одонтогенном остеомиелите челюстей указывает на необходимость включения в комплексное лечение препаратов, обладающих иммунокоррегирующими свойствами.

\section{Литература}

1. Харитонов, Ю. М. Диагностика тяжелых гнойных осложнений челюстно-лицевой области и шеи [Текст] / Ю. М. Харитонов, А.Л. Громов // Новые технологии в стоматологии: тез. докл. XVI Междунар. конф. челюстнолицевых хирургов и стоматологов. - СПб, 2011. - 213 с.

2. Маланчук, В. А. Электронейрография в ранней диагностике острого одонтогенного остеомиелита нижней челюсти [Текст] / В. А. Маланчук, Л. Л. Павловский // Хирургическая стоматология. -2014 - С. 39-43.

3. Мащенко, И. С. Состояние минеральной плотности костной ткани у больных одонтогенными воспалительно-деструктивными заболеваниями челюстно-лицевой области [Текст] / И. С. Мащенко, А. А. Гударьян // Вісник стоматології. - 2012. - № 4. - С. 56-63.
4. Козин, Д. В. Проблемы стандартизации антибактериальной терапииострого одонтогенного остеомиелита в стационарной хирургической практике Пензенской области [Текст] / Д. В. Козин, О. П. Родина, И. Я. Моисеева, П. В. Иванов // Известия высших учебных заведений. Медицинские науки. - 2009. - № 4. - С. 83-89.

5. Тимофеев, А. А. Руководство по челюстно-лицевой хирургии и хирургической стоматологии: учеб. пособ. [Текст] / А. А. Тимофеев; 5-изд., перераб. и доп. - К. : Червона Рута-Туре, 2012. - 1048 c.

6. Хирургическая стоматология: учебник [Текст] / под общ. ред. В. В. Афанасьева. - М.: ГЭОТАР-Медиа, 2011. $-880 \mathrm{c}$.

7. Коротких, Н. Г. Абсцессы и флегмоны лица: диагностика, лечение, прогноз [Текст] / Н. Г. Коротких, Г. В. Тобоев. - Воронеж: ИПО СОИГСИ, 2010. - 90 с.

8. Баранник, Н. Г. Изучение факторов, влияющих на распространенность острого одонтогенного остеомиелита среди жителей промышленного города Запорожья [Текст] / Н. Г. Баранник, С. Д. Варжапеиян, И. В. Куропата, И. В. Бердюк // Актуальне питання фармацевтичної науки та практики. - 2014. - № 2 (15). - С. 81-84.

9. Тобоев, Г. В. Оценка иммунологического статуса больных с пролонгированным течением острой одонтогенной инфекции и его значение в прогнозе заболевания [Текст] / Г. В. Тобоев, Н.Г. Коротких // Российский онкологический журнал. - 2009. - № 1. - С. 32-33.

10. Кабанова, А. А. Особенности клинических характеристик у пациентов с одонтогенными флегмонами одного клетчаточного пространства на современном этапе [Текст] / А. А. Кабанова, И. О. ПоходенькоЧудакова // Сборник научных трудов, Минск. - 2010. C. $54-57$.

11. Левицкий, А. П. Пребиотики и проблема дисбактериоза [Текст] / А. П. Левицкий, Ю. Л. Волянский, К. В. Скидан. - Харьков: ЭДЭНА, 2008. - 100 с.

12. Hellstein, J. W. Managing the care of patients receiving antiresorptive therapy for prevention and treatment of osteoporosis: executive summary of recommendations from the American Dental Association Council on Scientific Affairs [Text] / J. W. Hellstein, R. A. Adler, B. Edwards et al. // The Journal of the American Dental Association. - 2011. Vol. 142, Issue 11. - P. 1243-1251.

doi: 10.14219/jada.archive.2011.0108

13. Harik, N. C. Management of acute hematogenous osteomyelitis in children [Text] / N. C. Harik, M. S. Smeltzer // Expert Review of Anti-infective Therapy. - 2010. - Vol. 8, Issue 2. - P. 175-181. doi: 10.1586/eri.09.130

14. Mulcahey, M. Compartment syndrome in a child secondary to acute osteomyelitis of the ulna [Text] / M. Mulcahey, N. Thakur // The Pediatric Infectious Disease Journal. 2009. - Vol. 28, Issue 3. - P. 258-259.

doi: 10.1097/inf.0b013e318198284f

15. Yomagishi, Y. Septic arthritis and acute hematogeneus osteomyelitis in chilhood at a tertiary hospital in Japan [Text] / Y. Yomagishi, M. Toga // Pediatrics International. 2009. - Vol. 51. - P. 371-376. doi: 10.1111/j.1442200x.2008.02740.x

16. Юдина, Н. А., Использование лонгидазы в комплексной фармакотерапии хронического генерализованного пародонтита [Текст] / Н. А. Юдина, Н. А. Конопля, А. Л. Локтионов // Фундаментальные исследования. 2010. - № 10. - С. 100-106.

17. Походенько-Чудакова, И. О. Сепсис у пациентов c гнойно-воспалительными заболеваниями челюстнолицевой области. Учебно-методическое пособие [Текст] / И. О. Походенько-Чудакова, О. П. Чудаков, Ю. М. Казакова. - Минск: БГМУ, 2011. - 137 с. 


\section{References}

1. Kharitonov, Yu. M., Gromov, A. L. (2011). Diagnostika tyazholikh gnoynikh oslozhneniy chelustno-licevoy oblasti i shei [Diagnosis of severe suppurative complications of maxillofacial area and neck]. Novie technologii v stomatologii: XVI Mezhdunarodnaya konpherenciya chelustno-licevich khirurgov i stomatologov. SPb., 213.

2. Malanchuk, V. A., Pavlovskiy, L. L. (2014). Electroneyrographiya $\mathrm{v}$ ranney diagnostike ostrovo odontogenovo osteomielita nizhney chelusti [Electroneurogram in the early diagnosis of acute odontogenic osteomyelitis of the mandible]. Chirurgicheskaya stomatologiya, 2, 39-43.

3. Mashenko, I. S., Gudaryan, A. A. (2012). Sostoyaniye mineralnoy plotnosti kostnoy tkani u bolnikh odontogennimi vospalitelno-destruktivnimi zabolevaniyami chelustno-licevoy oblasti [The state of bone mineral density in patients with odontogenic inflammatory-destructive diseases of the maxillofacial region]. Visnik stomatologii, 4, 56-63.

4. Kozin, D. V., Rodina, O. P., Moiseeva, P. V. (2009). Problemi standartizathii antibakterialnoy terapii ostrovo odontogenovo osteomielita $\mathrm{v}$ stathionarnoy khirurgicheskoy praktike Penzenskoy oblasti [Problems of standardization of antibiotic therapy of acute odontogenic osteomyelitis in inpatient surgical practice Penza region]. Izvestiya vishikh uchebnikh zavedeniy, 4, 83-89.

5. Tymofeev, A. A. (2012). Rukovodstvo po chelustnolicevoy khirurgii I khirurgicheskoy stomatologii [Guidelines for oral and maxillofacial surgery and surgical dentistry]. Kiev. Chervona-Ruta, 1048.

6. Aphanasyev, V. V. (Ed.) (2011). Chirurgicheskaya stomatologiya [Oral Surgery]. Moskva. GEOTAR-Media, 880.

7. Korotkich, N. G., Toboev, G. V. (2010). Abscessi i phlegmoni lica: diagnostika, lechenie, prognoz [Abscesses and cellulitis person: diagnosis, treatment, prognosis]. Voronezh: IPO SOIGSI, 90.

8. Barannik, N. G., Varzhapetyan, S. D., Kuropta, I. V., Berduk, I. V., (2014). Izuchenie phactorov, vliyayushikh na rasprostranennosts ostrovo odontogenovo osteomielita sredi zhiteley promishlenovo goroda Zaporozhya [A study of factors affecting the prevalence of acute odontogenic osteomyelitis among residents of the industrial city of Zaporizhia]. Aktualne pitannya farmacevtichnoy nauki ta praktiki, 2 (15), 81-84.

9. Toboev, G. V., Korotkikh, N. G. (2009). Othenka immunologicheskovo statusa bolnikh s prolongirivannim tech- eniem ostroy odontogennoy inphekthii i evo znacheniye $\mathrm{v}$ prognoze zabolevaniya [Evaluation of the immunological status of patients with prolonged course of acute odontogenic infection and its importance in the prognosis of the diseas]. Rossiyski onkologicheski zhurnal, 1, 32-33.

10. Kabanov, A. A., Pokhodenko-Chudakova, I. O. (2010). Osobennosti кlinicheskikh kharakteristik u pacientov s odontogennimi phlegmonami odnovo kletchatochnovo prostranstva na sovremenom etape [Features of the clinical characteristics of patients with odontogenic phlegmon of cellular spaces at the present stage]. Sbornik nauchnikh trudov. Minsk, $54-57$.

11. Levitsky, A. P., Volyanski, Yu. L., Skidan, K. V. (2008). Probiotiki I problema disbakterioza [Probiotiki and the problem of dysbiosis]. Kharkov, 100.

12. Hellstein, J. W., Adler, R. A., Edwards, B. et al. (2011). Managing the care of patients receiving antiresorptive therapy for prevention and treatment of osteoporosis: executive summary of recommendations from the American Dental Association Council on Scientific Affairs. The Journal of the American Dental Association, 142 (11), 1243-1251. doi: 10.14219/jada.archive.2011.0108

13. Harik, N. C., Smeltzer, M. S. (2010). Management of acute hematogenous osteomyelitis in children. Expert Review of Anti-infective Therapy, 8 (2), 175-181. doi: 10.1586/eri.09.130

14. Mulcahey, M., Thakur, N. (2009). Compartment syndrome in a child secondary to acute osteomyelitis of the ulna. The Pediatric Infectious Disease Journal, 28 (3), 258-259. doi: 10.1097/inf.0b013e318198284f

15. Yomagishi, Y., Toga, M. (2009). Septic arthritis and acute hematogeneus osteomyelitis in chilhood at a tertiary hospital in Japan. Pediatrics International, 51, 371-376. doi: 10.1111/j.1442-200x.2008.02740.x

16. Yudina, N. A., Konoplya, N. A., Loktionov, A. L. (2010) Ispolzovaniye longidazi v kompleksnoy pharmakoterapii khronicheskovo generalizovanovo parodontita [Using Longidaza in complex pharmacotherapy of chronic generalized periodontitis]. Phundamentalniye issledovaniya, 10, 100-106.

17. Pokhodenko-Chudakova, I. O., Chudakov, O. P., Kazakova, Yu. M. (2011). Sepsis u pacientov s gnoynovospalitelnimi zabolevaniyami chelustno-licevoy oblasti [Sepsis in patients with purulent-inflammatory diseases of the maxillofacial region]. Minsk: BGMU, 13.

Дата надходження рукопису 25.12.2015

Баранник Неонилла Гавриловна, доктор медицинских наук, профессор, заведующий кафедры хирургической и терапевтической стоматологии, ГЗ «Запорожская медицинская академия последипломного образования МЗ Украины», ГУ «Городская клиническая больница экстренной и скорой медицинской помощи», ул. Победы, 80, г. Запорожье, Украина, 69005

E-mail: zmapo29@gmail.com

Варжапетян Сурен Диасович, ассистент, кандидат медицинских наук, кафедра хирургической и терапевтической стоматологии, ГЗ «Запорожская медицинская академия последипломного образования МЗ Украины», ГУ «Городская клиническая больница экстренной и скорой медицинской помощи», ул. Победы, 80, г. Запорожье, Украина, 69005

E-mail: suren-wargapetyan@rambler.ru 